\title{
Het betrappen van leugenaars
}

Aldert Vrij ${ }^{*}$

\section{Inleiding}

In deze bijdrage wil ik in het kort ingaan op mogelijkheden om leugenaars te betrappen. Eerst wil ik bespreken hoe goed mensen zijn in het betrappen van leugenaars. Het blijkt dat mensen hierin niet goed zijn en ik zal beschrijven waarom dat zo is. Voorts zal ik aangeven hoe mensen hun vaardigheden om leugens op te sporen kunnen verbeteren. Tenslotte zal ik ingaan op de accuratesse van enkele wetenschappelijke leugenontmaskeringstechnieken die onderzoekers in de loop der jaren hebben ontwikkeld. Deze bijdrage is te beschouwen als een beknopte weergave van een boek dat ik over liegen en het betrappen van leugenaars heb geschreven (Vrij, 1998). Voor meer informatie over dit onderwerp, alsmede voor literatuurverwijzingen, verwijs ik naar dit boek.

\section{Hoe goed zijn waarnemers in het betrappen van leugenaars?}

In principe is een leugenaar op drie manieren te ontmaskeren. In de eerste plaats door goed op te letten hoe hij zich gedraagt en hoe hij de dingen zegt. Een tweede manier is door nader te onderzoeken wat de leugenaar zegt, dus door de informatie die hij geeft te verifiëren. Ten slotte is een leugen op te sporen door fysiologische reacties bij de vermeende leugenaar te meten.

Experimenteel onderzoek laat zien dat mensen eigenlijk niet zo goed zijn in het ontmaskeren van leugenaars. In zulk onderzoek confronteert men waarnemers met videobeelden van verschillende personen (onbekenden, maar ook vrienden

* Dr Aldert Vrij (1960) is als Reader in Applied Social Psychology verbonden aan de Psychology Department van de University of Portsmouth (UK). Correspondentie over dit artikel sturen aan: Aldert Vrij, University of Portsmouth, Psychology Department, King Henry Building, King Henry 1 Street, Portsmouth PO1 2DY, United Kingdom of via e-mail: vrija@port.ac.uk 
of partners) die hen al dan niet voorliegen. Voor ieder persoon dienen ze aan te geven of de betreffende persoon loog dan wel de waarheid sprak. Waarnemers achterhalen doorgaans tussen de 45 en 60 procent van de leugens en waarheden, terwijl door louter te gokken al 50\% juiste classificeringen is te verwachten. Ze overtreffen deze gokkans dus niet of nauwelijks. Tevens blijkt uit onderzoek dat 'leken' en 'professionele leugenontmaskeraars', zoals douaniers en politiemensen, niet verschillen in hun vermogen leugens op te sporen. Wel is het zo dat professionele leugenontmaskeraars zekerder van zichzelf zijn, met andere woorden: hun beroep leidt ertoe dat ze leugens dènken te kunnen opsporen, niet dat ze er daadwerkelijk beter in worden.

\section{Waarom zijn mensen slecht in het betrappen van leugenaars?}

Er zijn drie redenen aan te voeren waarom mensen niet zo goed zijn in het betrappen van leugenaars, namelijk: het ontbreken van motivatie om leugens op te sporen, gebrekkig inzicht in de manier waarop leugens zijn te doorgronden en het feit dat sommige mensen zeer goede leugenaars zijn en daarom moeilijk zijn te betrappen.

\section{Gebrek aan motivatie}

Leugens worden vaak niet achterhaald omdat degenen die bedrogen worden die leugenaars niet willen ontmaskeren. Ze willen dat niet omdat ze er geen baat bij hebben of omdat ze geen raad weten met de verkregen informatie. De meeste gasten zullen bijvoorbeeld niet proberen te achterhalen of de gastheer het cadeau echt wel mooi vindt. Want wat schiet men op met die kennis? Ook meer ernstige leugens blijven daarom onopgemerkt. Veel ouders verbieden hun kinderen te roken terwijl deze dat stiekem toch doen. Dit blijft vaak onopgemerkt door toedoen van de ouders zelf. Het probleem is namelijk dat ze iets zullen moeten ondernemen als ze er achter komen dat hun kinderen roken. Veel ouders zullen echter niet goed weten wat te ondernemen en doen daarom maar geen moeite om te achterhalen of hun kinderen roken. Ook zal de echtgenoot niet altijd trachten uit te vinden of zijn vrouw overspel pleegt. Hoe namelijk te handelen als blijkt dat dit inderdaad het geval is? Zodra hij zijn vrouw met haar overspel confronteert, kan zij zich gedwongen voelen om te kiezen en misschien besluiten hem te verlaten, iets wat hij wellicht helemaal niet wil. Kortom, de mogelijke gevolgen kunnen voor de echtgenoot zo groot en ongewenst zijn dat het maar beter is alles te laten zoals het is.

Ekman (1985) is van mening dat ook de Britse premier Chamberlain de waarheid eigenlijk niet wilde weten toen hij Hitler ontmoette op 15 september 
1938 , in een poging de Tweede Wereldoorlog te voorkomen. Hitler was van plan Tsjecho-Slowakije binnen te vallen, maar zijn leger was er nog niet klaar voor. Als hij de Tsjechen zo ver zou weten te krijgen om zich niet te mobiliseren, zou hij binnen een paar weken gereed zijn om een verrassingsaanval uit te voeren. In de ontmoeting met Chamberlain verzwijgt Hitler zijn oorlogsplannen en verzekert hij Chamberlain Tsjecho-Slowakije niet te zullen binnenvallen. Voorwaarde was wel dat de Tsjechen zich niet zouden mobiliseren. Chamberlain doorzag de leugen niet en heeft geprobeerd de Tsjechen ervan te overtuigen zich niet te mobiliseren zolang de onderhandelingen met Hitler nog gaande waren. $\mathrm{Na}$ de ontmoeting met Hitler schrijft Chamberlain aan zijn zus: '...in spite of the hardness and ruthlessness I thought I saw in his face, I got the impression that here was a man who could be relied upon when he had given his word...' (Ekman, 1985, p 15/16). Thuis aangekomen verklaart Chamberlain in het parlement ervan overtuigd te zijn dat Hitler meende wat hij had gezegd. Het heeft er dus alle schijn van dat Chamberlain Hitler geloofde. Ekman is van mening dat Chamberlain dit deed omdat hij Hitler wel moest geloven. Als hij zou toegeven dat Hitler zich niet aan z'n woord zou houden, zou hij moeten toegeven dat zijn verzoeningspolitiek had gefaald en dat deze politiek Europa en Engeland in gevaar had gebracht.

\section{Gebrekkige kennis}

Soms liggen de zaken anders. De klant wil weten of de tweedehands auto inderdaad wel zo goed is als de verkoper beweert; de werkgever wil weten of de sollicitant werkelijk wel zo geschikt is als deze suggereert; de douanier wil weten of de reiziger echt niets heeft aan te geven en de rechercheur wil weten of de verdachte de waarheid spreekt als hij zegt onschuldig te zijn. Maar ook als mensen moeite doen om een leugenaar te betrappen, lukt dat dikwijls dus niet. Dit komt onder meer omdat mensen op verkeerde aanwijzingen letten als ze leugenaars willen betrappen. Er blijken bijvoorbeeld vastomlijnde ideeën te bestaan over hoe leugenaars zich gedragen. Mensen gaan er onder meer vanuit dat leugenaars hakkelend spreken, wegkijken, (glim)lachen en veel bewegingen maken. Dit komt omdat men veronderstelt dat leugenaars zenuwachtig zijn en daarom zenuwachtig gedrag zullen vertonen. De genoemde gedragingen zijn allemaal uitingen van zenuwachtig gedrag.

Vaak is het echter zo dat leugenaars die zenuwachtig zijn, geen zenuwachtig gedrag vertonen, bijvoorbeeld omdat ze zulk gedrag onderdrukken. Leugenaars realiseren zich bijvoorbeeld vaak dat friemelbewegingen en wegkijken een ongeloofwaardige indruk maken en proberen daarom zich zo normaal mogelijk te gedragen. Het controleren van gedragingen is echter niet altijd even gemakkelijk. Mensen zijn betrekkelijk goed in het controleren van hun gezicht, in het 
controleren van aankijken en (glim)lachen. Het gezicht speelt een belangrijke rol in de informatie-overdracht. We kunnen er bijvoorbeeld mee aangeven of we vrolijk of verdrietig zijn, of we iets begrijpen en of we het woord willen nemen. We zijn daarom getraind in het controleren van gelaatsuitdrukkingen. Bewegingen spelen over het algemeen een minder belangrijke rol in het overbrengen van informatie: we zijn er dus minder in geoefend en kunnen ze daarom minder goed controleren. Dat blijkt ook uit leugenonderzoeken. Leugenaars en waarheidsprekers verschillen niet van elkaar in wegkijken en (glim)lachen, maar wel in subtiele bewegingen, zoals been/voetbewegingen en hand/vingerbewegingen: leugenaars maken doorgaans minder van zulke bewegingen dan waarheidsprekers. ${ }^{1}$ Er zijn twee redenen waarom leugenaars deze bewegingen beperken. Dit heeft in de eerste plaats te maken met het te sterk controleren van die bewegingen. Leugenaars realiseren zich dat waarnemers op zulke bewegingen letten en proberen daarom om ze achterwege te laten. Maar omdat mensen normaal gesproken altijd wel zulke bewegingen maken, is een afname van die bewegingen dan het gevolg. In de tweede plaats is liegen soms moeilijker dan het spreken van de waarheid. De leugenaar moet er bijvoorbeeld voor zorgen dat hij zich niet verspreekt. Daarom moet hij harder nadenken als hij liegt. Hard nadenken leidt echter vrijwel automatisch tot een afname in beweeglijkheid. Dit is trouwens gemakkelijk na te gaan. Vraag iemand wat hij drie dagen geleden heeft gegeten en u zult zien dat de meeste mensen tijdens het nadenken wat zullen verstarren.

1 Hiermee is dus niet gezegd dat leugenaars altijd minder bewegingen maken. Er bestaan namelijk geen specifieke non-verbale of verbale kenmerken van liegen. Verschillende leugenaars gedragen zich anders en zeggen andere dingen. Bovendien hangt het vertoonde gedrag ook nog van de situatie af. Wel is het zo dat bij leugenaars de bewegingen vaker afnemen dan toenemen. 
Kortom, leugenaars zijn eerder te betrappen door op hun bewegingen te letten dan door naar hun gezicht te kijken. Toch wil dit niet zeggen dat het gezicht geen informatie over liegen biedt. Het tegendeel is eerder waar. Soms is van het gezicht af te lezen dat iemand liegt, maar dan moet u niet op wegkijken en (glim)lachen letten, maar op emotionele uitdrukkingen in het gezicht ${ }^{2}$. Emoties gaan automatisch gepaard met gelaatsuitdrukkingen. Vreugde uit zich bijvoorbeeld in opgetrokken uiteinden van de mondhoeken en een samentrekking van de spier bij de ooghoeken die kraaiepootjes veroorzaken; kwaadheid uit zich door versmalling van de lippen en naar beneden getrokken wenkbrauwen; angst uit zich door omhoog- en naar elkaar toegetrokken wenkbrauwen. Als iemand beweert niet bang te zijn terwijl hij dat wel is, moet hij er dus voor zorgen dat hij de bijbehorende gezichtsuitdrukking onderdrukt. Dat is moeilijk, zeker omdat dergelijke emoties vaak onverhoeds opkomen. Mensen nemen bijvoorbeeld meestal niet een bewuste beslissing om bang te worden, dat worden ze plotseling als gevolg van een bepaalde gebeurtenis. Het is zeer goed mogelijk dat een verdachte het ineens benauwd krijgt zodra hij in de gaten heeft dat de politie veel meer weet dan hij dacht. Op het moment dat hij bang wordt zal hij over het algemeen een angstige gelaatsuitdrukking vertonen, wat hem kan verraden. Hij zal daarom vliegensvlug proberen deze gelaatsuitdrukking te onderdrukken. Meestal zijn mensen daarmee te laat: de gelaatsuitdrukking is aanwezig, hoewel doorgaans niet langer dan 1/25 seconde. Dat is kort, zo kort dat een waarnemer deze uitdrukking al mist als hij met zijn ogen knippert op het moment dat de ander zo'n uitdrukking vertoont. Ze zijn zo kort omdat de ander probeert ze te onderdrukken. Desondanks zijn ze aanwezig omdat het erg moeilijk is om ze volledig te onderdrukken.

Het tegenovergestelde kan ook het geval zijn. Iemand kan een emotie voorwenden die er niet is: een moeder kan bijvoorbeeld tegen haar kind zeggen dat ze kwaad is, terwijl ze dat eigenlijk niet is. In zo'n geval zou de moeder om te overtuigen een kwade gelaatsuitdrukking moeten tonen. Er zijn echter maar weinig mensen die vrijwillig hun lippen op zo'n wijze kunnen versmallen dat het lijkt of ze kwaad zijn. Ook is het moeilijk om de indruk te wekken vrolijk te zijn als dit feitelijk niet het geval is. Bij een geveinsde lach zijn doorgaans de kraaiepootjes afwezig en het is maar weinig mensen gegeven zulke kraaiepootjes te laten zien als ze niet vrolijk zijn.

Ook is het lastig om een andere emotie voor te wenden dan die welke men feitelijk ervaart. Een overspelige echtgenoot kan bang zijn omdat zijn vrouw zoveel blijkt te weten, maar kan besluiten dit te verbloemen door te doen alsof

2 Zie Ekman (1985) voor een gedetailleerde weergave van de relatie tussen emotionele gezichtsuitdrukkingen en liegen. 
hij kwaad is op zijn echtgenote, bijvoorbeeld omdat zij hem 'zomaar' van overspel verdenkt. Hij zal dan de angstige gelaatsuitdrukking moeten onderdrukken en deze moeten vervangen door een kwade gezichtsuitdrukking. Dit is erg moeilijk, bijvoorbeeld omdat hij zijn wenkbrauwen naar beneden moet drukken om te doen alsof hij kwaad is, terwijl deze juist de neiging vertonen omhoog te gaan omdat hij bang is. Het letten op zulke micro-expressies van emoties biedt mogelijkheden om leugenaars te betrappen. Ik kom hier later op terug.

\section{Goede leugenaars}

Uiteraard is het zo dat de ene persoon beter kan liegen dan de andere persoon. Hoe beter de leugenaar is, hoe moeilijker het zal zijn om hem te betrappen. Wat bepaalt of iemand een goede leugenaar is? Dit hangt naar mijn idee samen met de aanwezigheid van cognitieve inspanning en emoties tijdens het liegen. Mensen voor wie liegen geestelijk niet inspannend is en die geen emoties ervaren tijdens het liegen, zijn goede leugenaars. Met andere woorden, een goede leugenaar voldoet aan ten minste vier kenmerken: (1) hij is origineel, (2) hij kan snel nadenken, (3) hij praat gemakkelijk en (4) hij heeft geen last van gevoelens van schuld, angst en opwinding.

Wat betreft originaliteit: een leugenaar kan voor verrassingen komen te staan. Een vrouw vindt bijvoorbeeld het telefoonnummer en adres van een onbekende dame in de jaszak van haar man en confronteert hem hiermee; de rechercheur vertelt de verdachte dat hij over een getuigeverklaring beschikt waarin staat dat de verdachte op het tijdstip van het misdrijf op de plaats van het misdrijf is gesignaleerd; de jongen krijgt van zijn moeder te horen dat, in tegenstelling tot wat hij zei, de winkels gewoon open zijn en de politicus die altijd heeft beweerd dat niet een zakenman maar zijn vrouw de hotelrekening heeft betaald, wordt ineens geconfronteerd met een afschrift waaruit blijkt dat zijn vrouw in die bewuste periode helemaal niet in het hotel aanwezig was. Om in zo'n situatie, maar ook in andere situaties, succesvol te kunnen zijn, moet een leugenaar meteen een geloofwaardig antwoord bij de hand hebben, wat spitsvondig denkwerk vergt.

Daarbij kan een leugenaar niet te lang wachten met het geven van dat geloofwaardige antwoord. De beoordelaar zou er achterdochtig van kunnen worden. Snel denkwerk is dus vereist.

In de derde plaats helpt het als een leugenaar een gemakkelijke prater is. Zijn welbespraaktheid kan hem dan mede van dienst zijn om zich uit benarde situaties te redden. Mensen die bijvoorbeeld veel woorden gebruiken om iets duidelijk te maken, zijn in het voordeel. Zij kunnen alvast met een breedsprakig antwoord beginnen zonder eigenlijk iets te zeggen. In de tussentijd kunnen ze nadenken over een goed antwoord. Of ze kunnen met hun welbespraaktheid 
anderen een rad voor ogen draaien door een overtuigend maar feitelijk nietszeggend antwoord te geven.

In de vierde plaats verschillen mensen in de emoties die ze ervaren tijdens het liegen. De ene verdachte zal, als hij liegt over zijn alibi, bang zijn dat hij wordt betrapt, terwijl de ander hiervan veel minder last zal hebben. De ene sollicitant zal zich enigszins schuldig voelen als hij tegen de commissie liegt over het salaris dat hij bij zijn huidige werkgever verdient, terwijl de andere sollicitant zonder enige schroom een te hoge opgave van zijn huidige salaris geeft. De ene leerling zal er meer schik in hebben als zijn smoes voor het te laat komen door de schooldirecteur wordt geloofd dan de andere leerling. Liegen is gemakkelijker als de leugenaar niet bang is om betrapt te worden, zich niet schuldig voelt en het liegen hem niet opwindt. Zo lang de leugenaar namelijk geen emotie ervaart, zal hij ook niet hoeven te proberen uitingen van emoties te onderdrukken en kan hij zich dus normaal gedragen. Het ontbreken van emoties kan te maken hebben met de frequentie van liegen. Hoe vaker iemand liegt, hoe minder opwindend het liegen zal worden en hoe minder schuldig de leugenaar zich eronder zal voelen. Ook kan vaak liegen ertoe leiden dat iemand er steeds gewiekster in wordt, wat de kans om betrapt te worden en daarmee ook de angst om betrapt te worden, doet afnemen. 


\section{Hoe zich te bekwamen in het betrappen van leugenaars}

Het betrappen van leugenaars is moeilijk. En omdat er geen specifieke verbale en non-verbale kenmerken van liegen bestaan, zal het wel altijd moeilijk blijven. Toch ben ik van mening dat veel mensen zich zouden kunnen verbeteren in het opsporen van leugenaars. Hopelijk kunnen de volgende raadgevingen hierbij helpen.

Leugens blijven nogal eens onopgespoord omdat beoordelaars te goeder trouw zijn en er vanuit gaan dat iemand de waarheid spreekt. Een vereiste voor een goede leugenontmaskeraar is dat hij achterdochtig is en bij alles wat iemand zegt zich afvraagt of dit waar is. Dit is moeilijk, zeker als de ander een goede bekende is, bijvoorbeeld uw partner. Mensen zijn doorgaans niet zo achterdochtig ten opzichte van hun partners. En dat is precies de reden waarom mensen niet goed zijn in het opsporen van leugens van hun partners.

Verder moeten beoordelaars doorvragen zodra ze vermoeden dat iemand een leugen vertelt. Het vertellen van een leugen wordt namelijk aanmerkelijk moeilijker als iemand doorvraagt. Hiervoor zijn verschillende redenen. De leugenaar mag zichzelf niet tegenspreken, moet opletten dat hij feiten die de waarnemer kent niet tegenspreekt en moet onthouden wat hij zegt zodat hij de informatie kan herhalen als dat van hem wordt verlangd. Bovendien moet hij al die tijd zijn gedrag beheersen, zodat hieruit geen aanwijzingen voortvloeien. Dit alles wordt moeilijker naarmate de beoordelaar langer doorvraagt. Hoe langer de beoordelaar doorvraagt, hoe groter de kans is dat de leugenaar tegen de lamp loopt.

Maar doorvragen is niet zo gemakkelijk als het lijkt. In de eerste plaats wordt doorvragen bemoeilijkt door het feit dat dit in strijd is met de heersende sociale spelregels. Iemand zal zeer snel geïrriteerd raken als wat hij zegt telkens door de ander met achterdocht wordt aangehoord en als de ander steeds om nadere uitleg vraagt. In de tweede plaats blijkt dat leugenaars - zeker in eerste instantie - een geloofwaardige indruk maken als er wordt doorgezaagd. Een mogelijke verklaring hiervoor is dat de waarnemer verwacht dat leugenaars in moeilijkheden raken zodra er wordt doorgevraagd en dat leugenaars daarom zullen gaan stotteren en zenuwachtig gedrag zullen gaan vertonen. Dit gebeurt echter lang niet altijd. Zolang de leugenaar erin slaagt zulk gedrag te vermijden, is de kans groot dat hij een geloofwaardige indruk op waarnemers maakt.

Het is van belang voor een leugenontmaskeraar om niet te veel informatie prijs te geven. Een leugenaar moet er immers voor zorgen de feiten die de waarnemer 
kent niet tegen te spreken. Deze taak is gemakkelijk als de leugenaar precies weet wat de beoordelaar weet. Het wordt heel wat moeilijker als de leugenaar niet precies op de hoogte is van de kennis van de waarnemer: want wat kan hij dan zeggen en wat niet? Als een waarnemer de leugenaar in het ongewisse laat over zijn kennis, bemoeilijkt hij dus de taak van de leugenaar.

Het betrappen van iemand op het vertellen van een leugen wordt aanmerkelijk gemakkelijker als de beoordelaar goed geïnformeerd is over het onderwerp waarover de leugenaar spreekt. Hoe meer gegevens de waarnemer kent, hoe groter de kans is dat de leugenaar iets zegt waarvan de waarnemer weet dat dit niet waar is.

Er bestaat geen specifiek gedrag dat op een leugen duidt. Evenmin is het zo dat alle leugenaars geneigd zijn bepaalde dingen te zeggen of juist achterwege te laten. Het is daarom niet zinvol om van stereotiepe opvattingen uit te gaan. In plaats hiervan dienen beoordelaars ieder geval afzonderlijk te bekijken. Goed kijken naar wat iemand doet en goed luisteren naar wat iemand zegt is hierbij vereist. Een korte emotionele gelaatsexpressie, verandering in het bewegingspatroon, een subtiele verspreking: het kunnen allemaal aanwijzingen zijn dat iemand liegt. Maar het is wel van belang niet te snel te oordelen. Stel bijvoorbeeld dat een verdachte ineens friemelende bewegingen maakt als hij zijn alibi toelicht. U kunt hieruit concluderen dat er wat aan de hand is, maar u kunt dan nog niet weten wat er precies aan de hand is. Het zou zo kunnen zijn dat hij friemelt omdat hij liegt en bang is om betrapt te worden. Ook is het mogelijk dat hij friemelt terwijl hij onschuldig is, bijvoorbeeld omdat hij bang is dat de politie hem niet gelooft ${ }^{3}$. Op grond van iemands gedrag is dus nooit met zekerheid te zeggen of iemand liegt. Er is slechts uit op te maken dat er iets aan de hand is. Mijn ervaring is dat politiemensen zich dit onvoldoende realiseren. In gesprekken die ik met rechercheurs voer, komen dikwijls uitspraken zoals 'Ik weet zeker dat hij liegt, want zodra het misdrijf ter sprake komt, kijkt hij me niet meer aan' aan de orde. Deze conclusie is te voorbarig. Als een verdachte steevast wegkijkt zodra hij over het misdrijf spreekt, kan dit heel goed betekenen dat er wat aan de hand is; het hoeft echter niet per sé te betekenen dat hij liegt. Ook een onschuldige verdachte kan wegkijken zodra het gesprek over het misdrijf gaat, bijvoorbeeld omdat hij het moeilijk vindt om te accepteren dat de politie hem van het plegen van een misdrijf verdenkt. Slechts met doorvragen en met

3. Zoals eerder opgemerkt, laten de meeste mensen overigens een vermindering in beweeglijkheid zien als ze liegen. 
het checken van de informatie die iemand geeft is na te gaan of het een leugen betreft of niet.

Bij het goed kijken ontstaat er overigens een probleem. Bewegingen van handen en voeten kunnen bijvoorbeeld van belang zijn bij het opsporen van leugens. Maar om dit soort gedragingen te bestuderen, moet de waarnemer de vermeende leugenaar letterlijk van top tot teen bekijken, wat in gesprekken meestal niet gebeurt en zelfs raar wordt gevonden. Meestal beperken we ons tot het kijken naar de ogen van de ander als we met iemand in gesprek zijn. Oogbewegingen leveren echter geen betrouwbare informatie over liegen op. In politieverhoren zou het daarom zinvol kunnen zijn om een andere rechercheur in een andere ruimte via een camera met het gesprek te laten meekijken. Zo'n rechercheur heeft immers wel de mogelijkheid om de verdachte van top tot teen te bestuderen.

\section{Succesvolle leugenontmaskeringstechnieken}

Al heel lang worden er pogingen ondernomen om leugenontmaskeringstechnieken te ontwikkelen. De Chinezen dwongen bijvoorbeeld vermeende leugenaars op rijstpoeder te kauwen en enige tijd later uit te spugen. Als het uitgespuugde poeder droog was, werd de persoon van het vertellen van een leugen beticht. Op dit moment zijn er enkele technieken bekend waarmee leugens en waarheden tot op zekere hoogte zijn op te sporen.

Als het gaat om non-verbale leugenontmaskeringstechnieken is het instrument dat Ekman en zijn collega's hebben ontwikkeld de meest gedetailleerde. Zij letten op de eerder beschreven emotionele gelaatsuitdrukkingen en kunnen hiermee $80 \%$ van de waarheden en $80 \%$ van de leugens opsporen. Het opmerken en juist interpreteren van zulke gelaatsuitdrukkingen is echter niet eenvoudig, omdat ze doorgaans zo kort duren. Waarnemers moeten speciaal worden getraind in het opmerken van zulke kortstondige emotionele gelaatsuitdrukkingen.

De meest bekende verbale leugenontmaskeringstechniek op dit moment is Statement Validity Assessment. Deze techniek is eind tachtiger jaren in Duitsland ontwikkeld. Het instrument bestaat onder meer uit een lijst van 19 criteria aan de hand waarvan transcripten (getypte letterlijke weergaven van iemands betoog) worden gescoord. Voorbeelden van criteria zijn 'Ongestructureerde reproductie', 'Noemen van details', 'Letterlijke reproductie van gesprekken' en 'Spontane verbeteringen'. Beoordelaars gaan aan de hand van de transcripten na of deze kenmerken in de verklaring voorkomen. Aangenomen wordt dat in verklaringen die op waarheid berusten meer van dit soort kenmerken voorkomen dan in 
leugenachtige verklaringen. Met gebruikmaking van deze methode kunnen zo'n $80 \%$ van de waarheden en $65 \%$ van de leugens worden opgespoord.

Fysiologische reacties worden gemeten met de polygraaf, in de volksmond leugendetector genoemd. Het woord leugendetector is echter misleidend omdat met zo'n apparaat geen leugens zijn op te sporen, maar slechts gespannenheid. De veronderstelling is dat leugenaars gespannen zijn; de polygraaf meet deze spanning. Polygraafonderzoeken tonen aan dat met een speciale ondervragingstechniek (de Controle Vraag Techniek) zo'n 70\% van de waarheden en bijna $90 \%$ van de leugens is te achterhalen.

Op grond van de hier genoemde percentages doet het enigszins vreemd aan dat in Nederland uitspraken over leugenachtigheid die zijn gebaseerd op Statement Validity Assessment wel als onafhankelijk steunbewijs in rechtszaken worden geaccepteerd maar polygraafuitkomsten niet. Dit kan in ieder geval niet zijn ingegeven door validiteitsmotieven, omdat polygraafuitkomsten misschien zelfs wel iets accurater zijn dan uitspraken gebaseerd op Statement Validity Assessment.

\section{Literatuur}

Ekman, P. (1985). Telling lies. New York: W. W. Norton.

Vrij, A. (1998). De psychologie van de leugenaar: Liegen en voorgelogen worden op het werk, in de rechtszaal en thuis. Lisse: Swets \& Zeitlinger. 